\title{
Estimating nonbelief: \\ Translation, cultural adaptation, \\ and statistical validation of the \\ Nonreligious-Nonspiritual Scale \\ in a nationwide Greek sample
}

\author{
Anna Polemikou* \\ University of the Aegean, Greece
}

\section{Eirini Zartaloudi*}

University College London, UK

\section{Nikitas Polemikos}

University of the Aegean, Greece

\begin{abstract}
Nonbelievers represent an understudied population in Greece. This investigation reports on the translation, cultural adaptation, and initial validation of the Nonreligious-Nonspiritual Scale (NRNSS), a measure designed to assess nonbelief. Data from 1754 participants were collected to examine the psychometric properties of the Greek version of the instrument and to assess the nationwide interpretability of the measure. Factor analyses suggested that the 16-item scale retained its bifactor model. Convergent validity was supported through associations with additional measures, namely, the Meaning in Life Questionnaire (MLQ) and the ConnorDavidson Resilience Scale (CD-RISC), which were used as reference criteria. Potential utility of the measure and future directions for ongoing development are discussed.
\end{abstract}

\section{Keywords}

Greek sample, factor analysis, nonbelief, NRNSS, translation

Greece is a religious nation. Based on the analysis of the Wave 7 data set (2017-2018) of the World Values Survey (WVS) composed of responses from 1200 participants in Greece, the vast majority

*These authors are joint first authors.

Corresponding author:

Anna Polemikou, Department of Preschool Education Sciences, School of Humanities, University of the Aegean, Kleovoulos Building, 1 Demokratias Ave., 85132 Rhodes, Greece. Email:

apolemikou@aegean.gr 
of Greeks identify as being religious $(81.4 \%$; $70 \%$ belong to the $18-29$ age cohort), rating the importance of God in their lives at an average of 8.1, along a 10-point rating scale, with $45 \%$ of respondents obtaining full marks at 10 points (Dianeosis, 2018). An impressive $91.7 \%$ believe in God, and $44.7 \%$ consider God an important aspect of their lives. It therefore comes as no surprise that scholarship on religion in Greece has traditionally focused on individuals with at least a mini-mal level of religiousness and, by effect, has overlooked other subgroups, including religious non-believers, which are the focus of this study.

Accordingly, regular participation in religious and/or spiritual (R/S) practices (i.e. ecclesiasti-cism) is common among Greeks, with nearly half of the population (40.9\%) attending religious services at least once a month, as opposed to the remainder, who exhibit either sporadic or nonex-istent ecclesiasticism. The vast majority (two out of three) pray "several times a week" - a disso-nant observation when one considers that an equivalent proportion (65.4\%) of interviewees disagree with the statement "when science and religion collide, religion is always right" (Dianeosis, 2018), in addition to which $12.2 \%$ explicitly declare their legitimate uncertainty. The underlying beliefs revealed in this statement collectively point toward a seemingly religious nation, whose noteworthy secular tendencies have been systematically under-investigated throughout the years.

Given the unique blend of religious and secular manifestations on behalf of Greek nationals, whereby the existence of a religious affiliation does not always coincide with theistic belief, the objective of this study was to culturally adapt and translate the Nonreligious-Nonspiritual Scale (NRNSS; Cragun, Hammer, \& Nielsen, 2015) and to examine its psychometric properties in the Greek context. The multiple expressions of the Greek Orthodox heritage are far-reaching and, in many ways, fused with the Greek State. Any cultural adaptation of R/S (or lack thereof; NR/NS) questionnaires should be evaluated in relation to the viewpoints of the nation's traditions (de Jager Meezenbroek et al., 2012). Adding to this point, a survey released by the Pew Research Centre (2018; conducted during 2015-2017) revealed that 76\% of contemporary Greeks consider it "very/ somewhat important to be a Christian to share their national identity," ranking fourth among 34 European countries who consider religion as a key component of national identity.

In national cultures and faith-based communities where religious socialization is common, spiritual practices are positively related to subjective well-being (i.e. Brewer-Smyth \& Koenig, 2014; Lun $\&$ Bond, 2013). The positive impact of spirituality on overall health has been extensively docu-mented in the literature (for a review, see Tabei, Zarei, \& Joulaei, 2016), whereas among atheists, deleterious effects on health and well-being have been associated with religious variables (Coleman, Hood, \& Streib, 2018). Yet the unique aspects of NR/NS typologies and distributions underlying these - as well as other related - empirical findings present a formidable problem for furthering our understanding of human functioning (Kapuscinski \& Masters, 2010), and for refining our scientific insight into theism and atheism, in which belief/nonbelief typologies and intersections remain visi-bly underexplored, misrepresented, and often controversial (Bishop, 2018; Mrdjenovich, 2019; Sevinc, Metinyurt, \& Coleman, 2017; Silver, Coleman, Hood, \& Holcombe, 2014).

In light of the above, the usefulness of a brief self-report inventory such as the NRNSS (Cragun et al., 2015) in contemporary research maintains an increasing currency. Similarly, this distinction represents a legitimate focus of research and is especially useful when applied to the Greek population, of which the vast majority aligns with the Christian faith (Orthodoxy; Pew Research Centre, 2018), regardless of whether this self-declared dominance represents a spiritual, religious, or national/cultural expression of identity and regardless of whether or not this identity coincides with theistic belief. As the more intrinsic dimensions of the religious (or NR) experience remain almost inaccessible to social surveys and analyses (Tsironis, 2012), a psychometric tool designed to highlight more intricate aspects of NR and NS diversity encountered among the religiously unaffiliated and/or nonbelievers carries vast implications deemed worthy of further exploration. 
One of the advantages of the NRNSS is that it is specifically designed to assess secularity at the micro or individual level (as opposed to the macro or societal level, and the meso or organizational/ institutional level). According to Marangudakis, Rontos, and Xenitidou (2013), "Greek civil soci-ety is shaped by a distinct 'civil religion' that constitutes the cultural background of Greek secular life" (p. iii). Indeed, $62 \%$ of contemporary Greeks express a willingness to keep religion separate from governmental policies (Pew Research Centre, 2018), which rather contradicts their funda-mental, pronounced, and complex relationship with religion in formations of personhood and civil selfhood. In that sense, the NRNSS successfully delineates two constructs that, though not tauto-logical, are often used interchangeably in the literature to connote one's relationship to religion- namely, religiousness and ecclesiasticism (i.e. adherence to forms of religious practices of principles of the Christian Church) - an approach which can be problematic in many ways. Furthermore, the NRNSS contains unambiguous, answerable items, which are informed by the themes of psychological universality and NR/NS multidimensionality, yet simultaneously allow for cross-cultural and individualistic variations in manifestations (Saroglou, 2011). We chose the NRNSS over existing nonbelief typologies (e.g. six types of nonbelief, Silver et al., 2014; dimen-sions of secularity, Schnell, 2015) as a tentative thematic coding for religious nonbelief, whose basic assumptions uphold an exploratory openness and would therefore facilitate the advancement of knowledge in what Silver et al. (2014) refer to as "a culturally dominant religious whole" (p. 990) landscape, as unique as that encountered in Greece.

More specifically, the purpose of this study was (1) to examine the NRNSS' construct validity by performing both an exploratory and a confirmatory factor analysis, (2) to evaluate the internal consistency of the scale, (3) to assess whether scores were affected by demographic factors, and (4) to evaluate its convergent and discriminant validity by checking its associations with the Meaning in Life Questionnaire (MLQ; Pezirkianidis, Karakasidou, Galanakis, \& Stalikas, 2016; Steger, Frazier, Oishi, \& Kaler, 2006) and the Connor-Davidson Resilience Scale (CD-RISC; Connor \& Davidson, 2003; Dimitriadou \& Stalikas, 2012).

The MLQ (Steger et al., 2006) is a measure of meaning-related variables and was used to iden-tify the Greek NRNSS' convergent validity. The MLQ's developers administered the 14-item Intrinsic/Extrinsic Religiosity Scale (IR/ER, respectively; Gorsuch \& McPherson, 1989) for convergent and discriminant validity testing, based on the premise that among the most fundamental human motivations is the desire to achieve deeper meaning and purpose, and independently attrib-ute meaning (for the sake of faith itself through spiritual commitment, that is, IR). This also reflects Emmons' (1999) position that spirituality involves "a search for meaning, unity, connectedness to nature, humanity, and the transcendent" (p. 877). Original MLQ scores correlated (though not excessively) with IR, suggesting that the two measures converge toward a common, but separate, construct. Contrarily, meaning was unrelated to ER (the component of religiousness that is divorced from spiritual meaning), which was taken as evidence of discriminant validity.

We also included the CD-RISC (Connor \& Davidson, 2003), a validated brief, self-rated meas-ure of sound psychometric properties used to quantify resilience in the general population and clinical samples, which taps on various dimensions of stress-coping abilities in the face of adver-sity. The scale's content provided a list of resilience traits, against which we could compare the NRNSS, including a spiritual resilience item, which assesses the role of faith and belief in benevo-lent intervention (i.e. "Sometimes faith and God can help").

The convergent validity of Greek NRNSS was examined through the correlation across measures of presence of, and search for, meaning, as well as traits that reflect the underpinnings of resilience-namely, (1) Trust in One's Instincts/Tolerance of Negative Affect/Strengthening Effects of Stress, (2) Positive Acceptance of Change/Secure Relationships, (3) Control, and (4) Spiritual Influences (SI). NR and NS scores were expected to be inversely related to meaning 
Presence scores, as religious engagement and spiritual faith are often instrumental means toward attaining meaning in people's lives, unlike the dimension of meaning Search which was expected to be positively related to NR and NS scores, as this dimension represents the active pursuit of meaning from multiple sources and/or outside a readily available framework.

Based on past scholarship and research, religious experience and beliefs may be associated with affect regulation (Saucier \& Skrzypinska, 2006), in which case we would expect NS and NR scores to be inversely related to salient features of resilience, such as Trust in One's Instincts/Tolerance of Negative Affect/Strengthening Effects of Stress, Positive Acceptance of Change/Secure Relationships, Control (i.e. realistic sense of control/having choices), and SI, as these dimensions are conceptually related to individualistic spirituality and/or IR. Finally, discriminant validity was assessed via correlations with the theoretically related-but different-resilience traits of Personal Competence/High Standards and Tenacity, which we hypothesized would be unrelated to both NRNSS measures.

\section{Method}

\section{Sample description}

A convenience sample of 1762 non-clinical Greek subjects was recruited by word of mouth, social media adverts, and physical presence on University campuses and Lifelong Learning Centers across Greece (Athens, Mytilene, Rhodes, and Thessaloniki).

Reports with omitted values exceeding $5 \%$ of scale items were dropped from the analysis $(N=$ 8). The final data set comprised data from 1754 subjects. For the remainder, missing values did not exceed 2\%. Little's (1988) Missing Completely at Random (MCAR) test, used to examine whether values were missing completely at random, was nonsignificant $\left(\mathrm{X}^{2}=15.82, p=.28\right)$, suggesting values were missing entirely by chance. Multivariate imputation by chained equations (MICE) was employed to deal with missing data.

Participants were $33.25( \pm 14.51)$ years of age on average, mostly female $(74.9 \%)$, and $91.9 \%$ of the entire sample were currently in higher education or held a university degree. Concerning religious denomination, predictably, most participants aligned with the Christian faith (72.22\%). A fifth of the sample self-identified as not having any religious affiliation (unaffiliated, sometimes also referred to as "nones," 20.45\%; all other religious denominations, including the open-ended choice "other," were less than $3.5 \%$ ), and $21.47 \%$ reported not believing in God or a higher power. Sample characteristics (including undisclosed values) are presented in full in Table 1.

To obtain evidence of the convergent validity of the NRNSS, participants also completed other measures, which were used as reference criteria. These measures were selected based on their availability in Greek and on the validity and reliability demonstrated for the Greek versions in previous studies.

\section{Measures}

The instruments used were the NRNSS, the MLQ, the CD-RISC, as well as questionnaire on demographic variables, described in Table 1, which were used as covariates in the analysis. These included self-declared theistic belief (assessed by means of a categorical (Yes/No/Don't know) variable, permitting identification groupings of believers/nonbelievers/uncertain) as well as selfdeclared religious affiliation (e.g. Christianity, Buddhism, Islam, Unaffiliated, Spiritual, Other).

NRNSS. The NRNSS, developed by Cragun et al. (2015), consists of 16 items, arranged in two subsections designed to assess the religiousness/nonreligiousness (NR) and spirituality/nonspirituality 
Table 1. Descriptive and inferential statistics for demographic information arranged by selfdeclared belief.

Demographic information

\begin{tabular}{|c|c|c|c|c|c|c|c|c|c|}
\hline & \multirow{2}{*}{\multicolumn{2}{|c|}{$\frac{\text { Totala }}{N=1754}$}} & \multirow{2}{*}{\multicolumn{2}{|c|}{$\frac{\text { Believers }}{n=990}$}} & \multirow{2}{*}{\multicolumn{2}{|c|}{$\begin{array}{l}\text { Nonbelievers } \\
n=375\end{array}$}} & \multirow[t]{3}{*}{$x^{2}$} & \multirow[t]{3}{*}{$p$} & \multirow[t]{3}{*}{ Cramer's $V$} \\
\hline & & & & & & & & & \\
\hline & $n$ & $\%$ & $n$ & $\%$ & \multicolumn{2}{|r|}{$\%$} & & & \\
\hline Genderb & & & & & & & 33.7 & $<.001$ & .10 \\
\hline Male & 440 & 25.1 & 204 & 20.6 & 135 & 36.0 & & & \\
\hline Female & 1313 & 74.9 & 786 & 79.4 & 240 & 64.0 & & & \\
\hline Age (years)b & & & & & & & 8.4 & .07 & .04 \\
\hline $18-25$ & 632 & 37.4 & 338 & 35.6 & 146 & 39.8 & & & \\
\hline 26-39 & 566 & 33.5 & 304 & 32.1 & 131 & 35.7 & & & \\
\hline $40-59$ & 435 & 25.7 & 267 & 28.1 & 81 & 22.1 & & & \\
\hline$>60$ & 57 & 3.4 & 40 & 4.2 & 9 & 2.4 & & & \\
\hline Educational levelb & & & & & & & 2.9 & .40 & .02 \\
\hline High school & 222 & 12.7 & 128 & 12.9 & 41 & 10.9 & & & \\
\hline Bachelor's & 1039 & 59.4 & 573 & 58.1 & 227 & 60.5 & & & \\
\hline Master's & 418 & 23.8 & 250 & 25.2 & 88 & 23.5 & & & \\
\hline Doctorate & 71 & 4.1 & 36 & 3.6 & 19 & 5.1 & & & \\
\hline Type of employmentb & & & & & & & 5.5 & .13 & .03 \\
\hline Full-time & 771 & 44.1 & 436 & 44.2 & 173 & 46.0 & & & \\
\hline Part-time & 297 & 16.9 & 149 & 15.1 & 67 & 17.8 & & & \\
\hline Unemployed & 595 & 34.1 & 343 & 34.8 & 124 & 33.0 & & & \\
\hline Retired & 85 & 4.9 & 58 & 5.9 & 12 & 3.2 & & & \\
\hline Religion & & & & & & & 783.5 & $<.001$ & .48 \\
\hline Christianity & 1261 & 72.2 & 904 & 91.4 & 89 & 23.8 & & & \\
\hline Unaffiliated & 357 & 20.4 & 23 & 2.3 & 266 & 71.1 & & & \\
\hline Spiritual & 59 & 3.4 & 35 & 3.5 & 8 & 2.1 & & & \\
\hline Other & 55 & 3.1 & 20 & 2.1 & 10 & 2.7 & & & \\
\hline Buddhism & 10 & 0.6 & 4 & 0.4 & 0 & 0 & & & \\
\hline Islam & 3 & 0.2 & 3 & 0.3 & 0 & 0 & & & \\
\hline Judaism & 1 & 0.1 & 0 & 0 & 1 & 0.3 & & & \\
\hline \multicolumn{10}{|l|}{ Measures } \\
\hline & $M$ & $S D$ & $M$ & $S D$ & $M$ & $S D$ & $t$ & $p$ & \\
\hline NRNSS & 49.3 & 13.6 & 41.6 & 9.9 & 64.2 & 11.0 & 1319 & $<.001$ & \\
\hline MLQ & 49.5 & 10.0 & 50.1 & 9.7 & 47.1 & 11.4 & 36.25 & $<.001$ & \\
\hline CD-RISC & 92.5 & 13.7 & 94.2 & 13.5 & 89.5 & 13.9 & 33.67 & $<.001$ & \\
\hline
\end{tabular}

SD: standard deviation; NRNSS: Nonreligious-Nonspiritual Scale; MLQ: Meaning in Life Questionnaire; CD-RISC: Connor-Davidson Resilience Scale.

aEntire sample composition: believers $=990$; nonbelievers $=375$; uncertain $=385$; undisclosed $=4$ (not shown). bMissing values: gender: 1 nonbeliever; age: 41 believers/9 nonbelievers; educational level: 3 believers/ 1 nonbeliever; type of employment: 4 believers; religion: 1 believer/ 2 nonbelievers. 
(NS) continuum, thereby assessing both the presence and absence of R/S. The former represents one's affiliation to institutional religiousness ("When faced with challenges in my life, I look to religion for support"), whereas the latter to individualistic spirituality ("I have a spirit/essence beyond my physical body"). Brief explanations introduce each subsection, in which "religion" is operationally defined and the term "spiritual" is conceptually placed along a vertical transcendence continuum (Sevinc et al., 2017). Scoring occurs along a 5-point Likert-type scale from 1 (strongly agree) to 5 (strongly disagree), assuming a total score range of 16-80. Reverse coding of items 4 and 7 was accounted for by subtracting individual scores on these items by 6 (the maximum possible item score, plus 1 ). Low scores reveal strong R/S, whereas high scores represent strong NR/NS. The authors reported a robust internal structure, with Cronbach's $\alpha>.94$ (Cragun et al., 2015).

During the cross-cultural adaptation process, the amphisemy attached to the Greek word for "spiritual," $\pi v \varepsilon \cup \mu \alpha t ı K o ́ S$, was regarded worthy of special consideration. The Greek linguistic equivalent represents an adjective which most commonly refers to mental/intellectual abilities or functions. In that sense, it is often used to describe persons possessing a highly developed intellect (i.e. political thinker/intellectual), although (depending on the context) it may also be used to describe nonmaterial and/or supernatural qualities. Although the meaning that the term acquired within the NRNSS context was operationally defined in the brief explanation/instructions of the original scale ("[. . . ] when you answer the items in THIS questionnaire we'd like you to think about 'spirituality' and 'spiritual' in the specific, SUPERNATURAL sense"), item 12 "All other things being equal, a spiritual person is better off" posed a rendering dilemma. We chose to render the statement conditional and retain the direct translation for pilot testing, rather than describe the term in a periphrastic way, and subsequently confirmed with the interviewees that the item retained semantic equivalence and clarity.

After the survey, the suitability of the NRNSS data was assessed by performing a KaiserMeyer-Olkin (KMO) test for sampling adequacy and Bartlett test for sphericity. The KMO (.94) and Bartlett $\left(\mathrm{X}^{2}=8845.16, p<.001\right)$ values showed that the scale was suitable for factor analysis.

MLQ. The MLQ (Steger et al., 2006) is a 10-item instrument rated on a 7-point Likert-type scale ( $1=$ absolutely true to $7=$ absolutely untrue $)$ and was used in its Greek form (Pezirkianidis et al., 2016; Stalikas, Kyriazos, Yotsidi, \& Prassa, 2018) for this study. It assesses meaning in life along two dimensions, namely, the presence of (items 1, 4, 5, 6, and 9) and the search for (items 2, 3, 7, 8 and 10) meaning in life. Presence evaluates whether respondents currently perceive a valued meaning in their lives (i.e. "I have discovered a satisfying life purpose"). Search represents an active exploration and/or ever-deepening pursuit of understanding life's purpose ("I am seeking a purpose or mission for my life"). Item 9 is reverse-coded and was accounted for by subtracting each participant's score on this item by 8 (the maximum possible item score, plus 1). Scale ratings range between 10 and 70, with those above the 24-point cutoff denoting high performance. Steger et al (2006) reported Cronbach's $\alpha$ coefficients ranging between .81 and .86 for the Presence and between .84 and .92 for the Search subscale. For the present study, sample internal consistency was .83 for Presence and .88 for Search.

$C D$-RISC. The Greek version of the CD-RISC (Connor \& Davidson, 2003; Dimitriadou \& Stalikas, 2012) measures individuals' perceived stress-coping and recovery abilities, as rated over the past month. It contains 25 items, representing five factors - (1) personal competence, high standards and tenacity; (2) trust in one's instincts, tolerance of negative affect, and strengthening effects of stress; (3) positive acceptance of change and secure relationships; (4) control; and (5) SI-and has been used in a wide range of samples and environments (Liu, Fairweather-Schmidt, Burns, \& 
Roberts, 2014). Items are rated on a 5-point Likert-type scale (0-4; total range, 40-125), with higher scores representing greater resilience, that is, scores above the 92-point cutoff suggesting high-resilience individuals (Stalikas et al., 2018). Connor and Davidson (2003) reported $\alpha=.89$ for the entire scale, whereas the present study sample yielded $\alpha=.90$.

\section{Translation method}

"Translate-retranslate" protocols (Solano-Flores, Backhoff, \& Contreras-Niño, 2009; Van de Vijver \& Hambleton, 1996) were implemented to translate the original NRNSS into Greek. Independent forward translations were completed by two translators, A.P. and E.Z., both native speakers of the target (i.e. Greek) and fluent in the source language (i.e. English). Following personal communications, the translators agreed upon the preliminary Greek version. For the cultural adaptation, this version was pilot-tested on three adult volunteers. Upon instrument completion, the three informants underwent a cognitive debriefing interview by A.P., assessing whether (1) each separate item was understandable, (2) they felt the need to reformulate the wording of certain items, and (3) any statements needed further clarification. To verify the original meaning, this ver-sion was also back-translated into the source language by the third author/translator, N.P., who was unaware of its original form.

The preliminary Greek versions, back-translation, and original scales were then compared for discrepancies. Adjustments were made to produce the final Greek version, resulting in an equivalent version to the original, both regarding linguistic structure, clarity, and semantic quality. The resulting Greek version is presented in Appendix 1.

\section{Procedure}

An electronic survey was created, which included an informative page regarding the purpose and content of the survey, the scale measures, and the demographic data questionnaire (please refer to Supplementary Table 1 for more information). Internet social media were used to broadcast the survey, and volunteers were recruited from the general population and completed the self-administrated questionnaires online. To minimize the likelihood of repeated participations (i.e. due to technical/connection failures and possible re-entries) by the same respondent(s), participants were given the option to voluntarily disclose their emails as identifiers, upon completion of the survey. The remainder were recruited in person and completed the hard-copy equivalent. Participation was voluntary and anonymous, and successful completion was taken to imply informed consent. Participants completed the NRNSS and the additional self-report inventories reported below. The survey was launched on 24 July 2018, and all testing was undertaken over a period of 90 days.

\section{Data analysis}

Data collected were coded and analyzed using the $R$ Project for Statistical Computing, v.3.3.2. The entire sample was randomly split into two equivalent data sets using the "sample" function in $R$, which employs a random generator algorithm. Sample-splitting is a cross-validation method which allows robust inferences regarding the factorial structure of the scale being studied (Brown, 2015; Byrne, 2016).

Reliability analyses were performed to evaluate internal consistency by calculating Cronbach's $\alpha$. Values .7 were considered acceptable (Nunnally \& Bernstein, 1994). Eventually, correlation analyses were conducted on the entire sample to investigate associations between gender, age, uppermost educational level, type of employment, religious denomination, (non)belief in a god/ 
deity or higher power, and the two NRNSS subscales that emerged from the factor analysis. The threshold of significance was set at .05 .

\section{Results}

\section{Demographic profiles of believers and nonbelievers}

Table 1 provides a full listing of sample specificities after quality control was performed. Participants have been classified into two groups, based on whether they declared belief or nonbelief in God or higher power. To determine whether there was a significant relationship between believers and nonbelievers, independent sample $t$-tests and chi-square $\left(\mathrm{X}_{2}\right)$ analyses were calculated (as shown in Table 1). Shapiro-Wilk tests were statistically significant for all 16 items of the NRNSS $(p<.001)$, suggesting a violation of the assumption of univariate normality. Similarly, significant Mardia's multivariate skewness and kurtosis tests $(p<.001)$ violated multivariate normality.

When considering different subgroups, the results herein established an invariance of belief and nonbelief between age groups (aged 18-25, 26-39, 40-59, and $>60$ years) supporting that an invariance holds across the lifespan, although a significant gender variance was also noted. Of those who said they did not believe in God $(n=375 ; 21.4 \%$ of the entire sample), 110 (28.6\% of nonbelievers) simultaneously self-identified as being religiously affiliated. Similarly, of those who stated uncertainty of God's existence ( $n=385 ; 21.4 \%$ of the entire sample), 311 (80.8\% of uncer-tain respondents) also indicated that they were part of a religious tradition.

Exploratory factor analysis (EFA) was performed in the first half of the sample $(n=877)$, whereas a confirmatory factor analysis (CFA) was performed in the second half of the sample $(n=877)$. We assessed goodness of fit with a variety of fit indices, as is widely recommended (namely, X2, comparative fit index (CFI), Tucker-Lewis index (TLI), standardized root mean square residual (SRMR), root mean square error of approximation (RMSEA)). For the $\mathrm{X}^{2}$ analysis, cutoff for good fit was $p>.05$, with values approximating zero indicating a better fit (Brown, 2015). Regarding CFI and TLI, values greater than 90 were considered good fit indices (Baumgartner \& Homburg, 1996; Hu \& Bentler, 1999). For the SRMR and RMSEA indices, values below .08 and .06, respectively (Brown, 2015; Hu \& Bentler, 1999), were considered acceptable.

\section{Establishing construct validity with EFA}

EFA was chosen as an extraction method and was conducted on the first half of the sample to establish factor structure and evaluate the NRNSS' construct validity. An oblique (nonorthogonal) rota-tion (direct oblimin technique) procedure was employed. For the EFA, the sample submitted comprised 877 individuals, mostly women $(73.89 \%)$, currently studying or holding a higher educa-tion degree $(88.34 \%)$, with a mean age of $33.4( \pm 16.02)$ years. Cutoff points were .40 for factor loadings and 1.00 for eigenvalues. EFA identified two factors (indicated in Figure 1). Factor 1 reflects one's affiliation to institutional religiousness, and Factor 2 expresses the notion of indi-vidualistic spirituality (Figure 2). All factor loadings were above .40 (Table 2), and there were no cross-loading items. The proportion of variance explained from the first and the second factor was .30 and .27 , respectively. Fit statistics supporting the model's fit are presented in Table 3.

\section{Confirming construct validity with CFA}

A CFA was performed on the second data set to further verify the underlying structure (bifactor model) which arose from the EFA as a good fit for the data. For the CFA, the sample comprised 877 


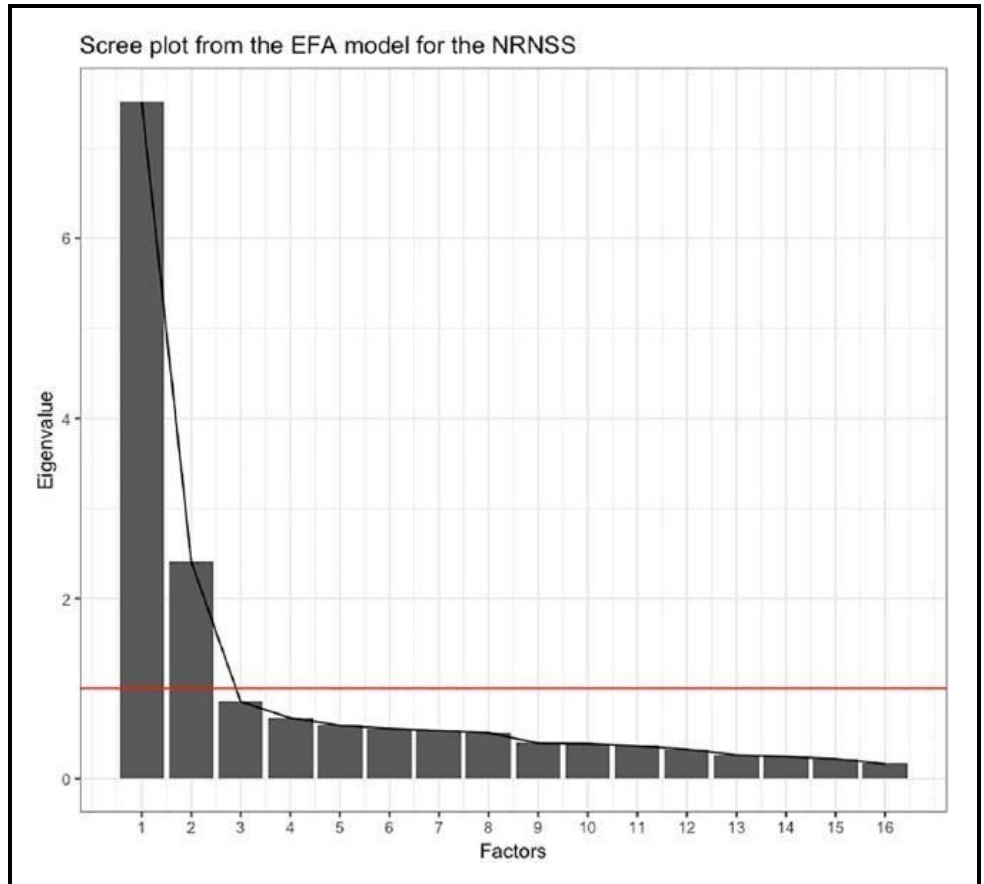

Figure 1. Scree plot illustrating the results from the EFA model for the NRNSS.

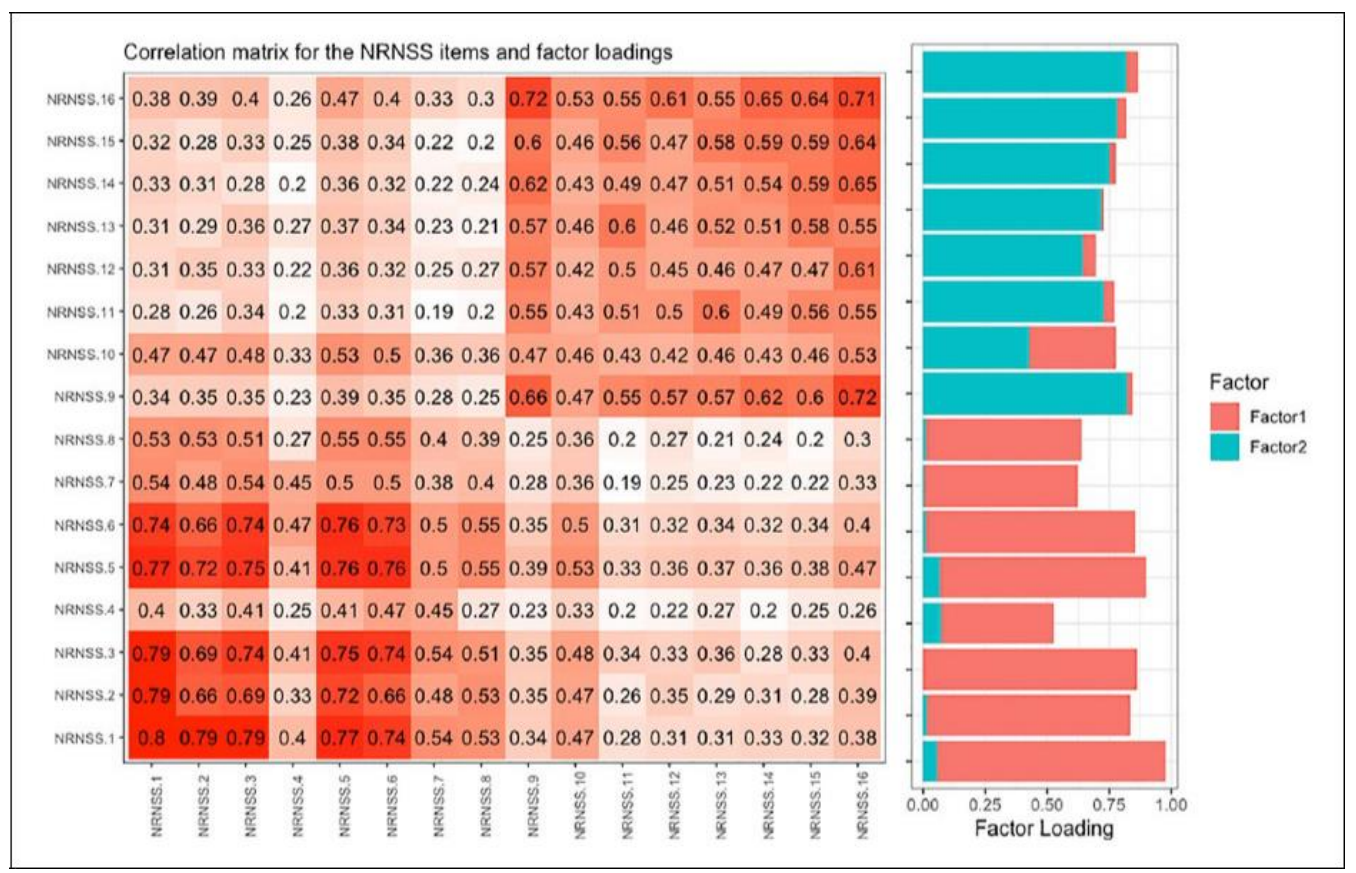

Figure 2. Correlation matrix for the NRNSS items and their factor loadings in the CFA model. 
Table 2. NRNSS item loadings per factor.

\begin{tabular}{lcc}
\hline & Factor 1 & Factor 2 \\
\hline Item 1 & .93 & -.06 \\
Item 2 & .84 & -.02 \\
Item 3 & .87 & .01 \\
Item 4 & .44 & .08 \\
Item 5 & .83 & .07 \\
Item 6 & .84 & .02 \\
Item 7 & .59 & .03 \\
Item 8 & .62 & .01 \\
Item 9 & -.03 & .83 \\
Item 10 & .34 & .43 \\
Item 11 & -.02 & .71 \\
Item 12 & .04 & .66 \\
Item 13 & .02 & .70 \\
Item 14 & -.03 & .76 \\
Item 15 & -.02 & .77 \\
Item 16 & .03 & .83 \\
\hline
\end{tabular}

NRNSS: Nonreligious-Nonspiritual Scale.

Extraction method: factor analysis; rotation method: direct oblimin.

Note: Items in bold represent factor loadings above the .40 cutoff.

Table 3. Summary of fit indices from the exploratory factor analysis model (with two factors) of the Greek Nonreligious-Nonspiritual Scale in 877 subjects, July-October 2018.

\begin{tabular}{llll}
\hline & Estimate & Reference \\
\hline $\mathrm{X}^{2}$ & 8845.16 & - & - \\
Comparative fit index (CFI) & .96 & & .90 \\
Tucker-Lewis index (TLI) & .95 & $\mathrm{Cl}: .049-.058$ & .90 \\
Root mean square error of approximation (RMSEA) & .05 & & .06 \\
Standardized root mean square residual (SRMR) & .03 & & .70 \\
$\alpha(\mathrm{NR} / \mathrm{NS})$ & $.91 / .88$ & & \\
\hline
\end{tabular}

a: Cronbach's $\alpha$; NR: nonreligious, NS: nonspiritual; Cl: 90\% confidence interval.

individuals, mostly women (75.91\%), currently studying or holding a higher education degree $(86.27 \%)$, and a mean age of $33.10( \pm 12.80)$ years. The CFA indicated a good fit of the twofactor model. For a summary of fit statistics, please refer to Table 4. Correlation patterns for the NRNSS items and factor loadings are presented in Figure 2.

\section{Reliability analysis}

Internal consistencies (Cronbach's $\alpha$; Cronbach, 1951) demonstrated robust internal structure for the NRNSS study sample, at $\alpha=.91$, which was equivalent to its original form (Cragun et al., 2015). Both subscales (NR, $\alpha=.91$; NS, $\alpha=.89$ ) displayed good reliability ( .70 considered acceptable, .80 adequate per Kline, 2016). All results considered together, the internal consistency of the Greek NRNSS was excellent. 
Table 4. Summary of fit indices from the confirmatory factor analysis model of the Greek Nonreligious-Nonspiritual Scale.

\begin{tabular}{llll}
\hline & Estimate & Reference \\
\hline X$^{2}$ & 556.21 & - & - \\
Comparative fit index (CFI) & .95 & & .90 \\
Tucker-Lewis index (TLI) & .93 & $\mathrm{Cl}: .056-.064$ & .90 \\
Root mean square error of approximation (RMSEA) & .06 & & .06 \\
Standardized root mean square residual (SRMR) & .05 & & .08 \\
a (NR/NS) & $.91 / .89$ & & .70 \\
\hline
\end{tabular}

a: Cronbach's $\alpha$; NR: nonreligious; NS: nonspiritual; Cl: 90\% confidence interval.

Table 5. Intercorrelations of NRNSS subscales and their correlations with MLQ and CD-RISC subscales.

\begin{tabular}{|c|c|c|c|c|c|c|}
\hline \multirow{2}{*}{ NRNSS } & \multicolumn{3}{|c|}{ Factor 1 (nonreligiousness) } & \multicolumn{3}{|c|}{ Factor 2 (nonspirituality) } \\
\hline & & & & & & \\
\hline Factor 1 & - & & & .49 & $* * *$ & $<.001$ \\
\hline Factor 2 & .49 & $* \star *$ & $<.001$ & - & & - \\
\hline \multicolumn{7}{|l|}{ MLQ } \\
\hline Presence & -.19 & $* * *$ & $<.001$ & -.25 & $\star * *$ & $<.001$ \\
\hline Search & -.06 & * & .02 & .25 & *** & $<.001$ \\
\hline \multicolumn{7}{|l|}{ CD-RISC } \\
\hline $\begin{array}{l}\text { Personal competence } \\
\text { High standards } \\
\text { Tenacity }\end{array}$ & -.02 & & .50 & -.12 & *** & $<.001$ \\
\hline $\begin{array}{l}\text { Trust in one's instincts } \\
\text { Tolerance of negative affect } \\
\text { Strengthening effects of stress }\end{array}$ & .04 & $* \star *$ & $<.001$ & -.17 & $* * *$ & $<.001$ \\
\hline $\begin{array}{l}\text { Positive acceptance of change } \\
\text { Secure relationships }\end{array}$ & .07 & ** & .005 & -.06 & ** & .008 \\
\hline Control & .23 & $* * *$ & $<.001$ & -.23 & $* * *$ & $<.001$ \\
\hline Spiritual influences & .64 & $* * *$ & $<.001$ & -.56 & $* * *$ & $<.001$ \\
\hline
\end{tabular}

NRNSS: Nonreligious-Nonspiritual Scale; MLQ: Meaning in Life Questionnaire; CD-RISC: Connor-Davidson Resilience Scale.

All scores are expressed as $r$ ( $p$ value).

${ }^{*} p \quad .05 ;{ }^{* *} p \quad .01 ;{ }^{* * *} p \quad .001$.

Comparisons between NRNSS subscales on gender, age, uppermost educational level, type of employment, religious denomination, and deity (non)belief are described in detail in Supplementary Table 1.

\section{Intersubscale correlations}

Intercorrelation measures for the subscales derived by EFA (affiliation to institutional religiousness (NR) and individualistic spirituality (NS)) were conducted as a way of analyzing internal consist-ency reliability and were found to be moderately positive $(r=.49, p<.001$; Table 5). Correlation patterns for the NRNSS items and factor loadings are presented in Figure 2. 


\section{Comparison between mean scores of the Greek version of the NRNSS and the original NRNSS (US sample)}

The mean scores obtained with the Greek version of the NRNSS were $3.9 \pm 1.0$ in the Institutional Religiousness subscale and $2.8 \pm 0.9$ in the Individualistic Spirituality subscale. Both scores were comparable to those obtained in the original study with a US. sample (3.4 \pm 1.2 and $3.0 \pm 1.0)$.

\section{Associations between NRNSS subscales according to demographic criteria}

In addition, $X_{2}$ tests were performed to investigate potential invariances on the scale's factors (NR and NS) as a function of demographic groupings explored in this study (shown in Supplementary Table 1). Notably, NS scores varied significantly (all $p$ s $<.001$ ) as a function of all the demo-graphic groupings designated in the present sample (i.e. gender, age groups, selfdeclared theistic belief, religious denomination, educational level, and type of employment). However, an invari-ance for NR scores occurred with regard to the criteria of (1) highest educational level completed and (2) type of current employment (i.e. part-time, full-time, unemployed, retired), which did not seem to significantly contribute toward producing similar NR score variances. Significant differ-ences emerged for the remaining demographic groupings ( $p$.1-.4), among which the strongest relationship was found to exist between NR and (1) belief and God and (2) religious denomination (both $p<.001$ ).

\section{Convergent/discriminant validity}

Convergent validity for the NRNSS emerged from the total sample $(N=1754)$ and is depicted in Table 5. Both NRNSS variables yielded weak, yet reliable, correlations with MLQ subscale scores, mostly of an inverse nature. This did not include NS, which was positively related to search for meaning. Weak positive relationships between NR and three out of five CD-RISC subscales (shown in Table 5) further lent themselves to evidence of convergent validity.

Surprisingly, however, NR maintained an unexpected strong positive relationship with SI scores. Conversely, NS scores were negatively related to SI, in keeping with our expectations. According to the broad interpretations of the CD-RISC's factor composition, the SI element denotes a stress-coping ability geared toward adapting body, mind, and spirit to life's circumstances, as a result of faith in a benevolent intervention (also see Brewer-Smyth \& Koenig, 2014; Currier, Drescher, \& Harris, 2014). A few speculations regarding this outcome can be drawn at this point. Technically, the item "Sometimes faith and God can help" is a double-barreled question (Lavrakas, 2008) touching upon more than one construct (i.e. faith and God), which unavoidably leads to problematic response formations. In that sense, faith can be taken to have no direct object; hence, respondents may freely establish a semantic relationship between faith and whichever truth they believe in.

Of note, the NRNSS covers four conceptual quadrants (NR/S, NR/NS, R/S, and R/NS), with each subscale representing a bifactorial compound, indirectly accounted for in the NRNSS scoring system. Further inferences can be drawn if either one of these typologies is found to coincide (or not) with one's self-declared theistic belief (which was assessed in this study using a categorical (Yes/No/Uncertain) variable). We decided to examine possible variable combinations between (non)believers - (un)affiliated, in light of findings that suggest that the proportion of Greek selfdeclared believers does not coincide with those who consider themselves religiously affiliated." Overall, NR maintained positive relationships to all CD-RISC constructs, as opposed to NS which was characterized by negative correlations to resilience ratings. These patterns of NR, NS, and resilience variables possibly carry residual interpretations based on the aforementioned compound 
NRNSS typologies, which may indicate that further effort is needed to specify the NR variable, as measured by the NRNSS.

Finally, NR and Personal Competence/High Standards and Tenacity were unrelated, and there-fore independent; thus, we can conclude that discriminant validity exists between the two meas-ures. Nevertheless, the weak but significant correlation of the aforementioned variable with NS may indicate that NR needs to be further investigated in relation to variations in NS typologies.

\section{Discussion}

This study provides empirical support for the reliability and validity of the Greek version of the NRNSS (Cragun et al., 2015). Adaptation was based on data collected from a nationwide sample of 1754 individuals, and the results showed that NRNSS established concrete psychometric fac-tors. The present survey documents a sizable population of religiously unaffiliated individuals. Although we did not specifically investigate the underlying schisms among the unaffiliated (i.e. those who identify as negative atheist, non-atheist, ritual atheist, agnostic atheist, or "nothing in particular," also known as "nones") (Coleman et al., 2018; Mrdjenovich, 2019; Sevinc et al., 2017), collective group membership amounted to $20.4 \%(n=357)$ of the entire cohort. The aforemen-tioned finding confirms estimates deriving from surveys in which Western European populations exhibit a $15 \%$ minimum consistency of unaffiliated respondents (Pew Research Centre, 2018).

A construct-related observation worth clarifying at this point is that although, in its entirety, the NRNSS was designed to capture the extent of one's R and S (or lack thereof, that is, NR and NS, respectively), the NS subscale encompasses the search for the spiritual/sacred both within and outside of traditional institutional religion, and therefore entails a strong religious component (Cragun et al., 2015). Given that Greece constitutes almost a cultural exception within Europe, in that religious affiliation (i.e. Orthodox Christianity) is very high compared to other European coun-tries (Pew Research Centre, 2018), the NRNSS' approach is in keeping with the cultural disposi-tion of most Greek nationals, who view Orthodoxy not only as a religious but also as a personal and/or national identity component (Dianeosis, 2018; Tsironis, 2012).

In stark contrast with other European countries (e.g. France) that founded their political forma-tion on Church-State separation (Tsironis, 2012), the Orthodox Church participated in the construc-tion of the contemporary Greek nation, representing a cultural and national continuity from antiquity to Byzantine times, and the national independence revolution against the Ottoman Empire domina-tion (1820-1829) (Molokotos-Liederman, 2003). To this day, Orthodox officials reserve exclusive institutionalized links with the Ministry of Education and Religious Affairs, as well as other privileges (i.e. governmental recognition of canon law in areas of civil law (i.e. marriage); financial support (i.e. clergy salaries, pensions, tax exemptions on revenues, etc.)). Popular state functions and national holiday celebrations are often jointly presided by State officials and Church leaders, further emphasizing the religious and national interlacing of identities in Greece. Overall, the con-stitutionally set entitlements of the "prevailing faith" are at the expense of minority faith and reli-giously unaffiliated cohorts (Alivizatos, 1999; Molokotos-Liederman, 2003), but need to be considered in light of the personal, social, and historical circumstances which shaped (and continue to inform) the expression of ecclesiasticism, as it often coincides with NR within the Greek context (Tsironis, 2012), notwithstanding the peculiarity of Greek folklife, customs, cultural heritage, and historical — as well as ongoing — national/political turbulence in Greece's geographical landscape.

In view of the above, it is possible that a social affiliation motivation (Van Cappellen, Fredrickson, Saroglou, \& Corneille, 2017), tradition-oriented religiousness (Saucier \& Skrzypinska, 2006), or civil forms of religiousness permeate and provide "a deep cultural substratum of Greek civil life" (Marangudakis et al., 2013, p. 2), which often presides over atheistic, NR, and/or NS 
identities. Subsequently, this may explain the large percentage of religiously affiliated, yet selfdeclared nonbelievers, witnessed in the present sample.

At this point, some limitations of the study should be noted. First, our analyses were based on volunteers who were likely particularly interested in R/S matters and keen on expressing their opinions, which may reflect a proportion of the population which is currently actively pursuing (rather than hav-ing settled) the formation of their R/S identity. Furthermore, it has to be mentioned that overrepresenta-tion is probably the most fitting description characterizing this ambitious demographic, especially regarding relatively young age, well-educated groups, and women far outnumbering males, which restricts the generalizability of our findings as this does not reflect the average Greek population.

\section{Concluding remarks and future directions}

Overall, the cross-cultural adaptation of Greek version of the NRNSS followed the established process recommended in the scientific literature, which yielded a scale successfully adapted to the Greek reality. Over 1750 respondents were registered in the present survey, which renders the large sample size among the strengths of our study. Taking all this under consideration, and examining the results from the CFA and the reliability analysis, we can affirm that the Greek version of the NRNSS both fits the original bifactor model and retains its reliability as a questionnaire that is fit for use with Greekspeaking populations. Such availability is expected to facilitate researchers who are interested in systematically comparing samples of different cultural backgrounds in cross-linguistic experimental paradigms and may prove to be particularly useful in delineating individual differences on the basis of quadrant NRNSS typologies (i.e. NR/S, NR/NS, R/S, and R/NS).

Furthermore, the variance of NRNSS' factor scores (NR and NS) as a function of demographic groupings (shown in Supplementary Table 1) seems to suggest that, as a personality theme, NS is more likely than NR to be influenced by demographic parameters, especially by self-declared reli-gious belief and religious denomination, even though both NR and NS appear to represent fluid constructs, if examined as functions of genetic and/or environmental factors (i.e. gender, age, etc), which presents a promising avenue for future exploration.

To conclude, the present development paves the way for a multitude of investigations implying the often neglected and under-researched concept of nonbelief and NR formations (Coleman et al., 2018; Schnell, 2015; Silver et al., 2014) in the general landscape of psychology, and in the fields of spirituality and religiosity in particular. Although the NRNSS alleviates any ambiguity between NR/S and NR/NS, it excludes other identities. Even though it was not our intention to give an exhaustive listing of the religiously unaffiliated and/or atheist formations in Greece, recent devel-opments approach atheism and NR as diversified and multiform concepts (i.e. non-theism, anti-atheism, ritual atheism/agnosticism, seeker-agnosticism, scientism, personal responsibility, humanism) (Coleman et al., 2018; Mrdjenovich, 2019; Schnell, 2015) to describe individuals who actively dissociate themselves from God and religion. These rising tendencies dictate a broader and deeper experiential and behavioral understanding of secular identities and worldviews, which war-rants further exploration in their own right, and may be facilitated by further examining the inter-esting interplay of quadrant NRNSS typologies within the Greek cultural context.

Prospective studies could expand our understanding of the variable manifestations of NR (i.e. R in the absence of denominational affiliation) and/or nonbelief in deity, by identifying specific contrasts and interrelations with various counterparts along the S/NS continuum (i.e. personal, functional, or positive spirituality; Saucier \& Skrzypinska, 2006). These include further investigating a range of associated phenotypes, such as personality differences, cognitive processing styles, behavioral genetic dispositions (i.e. heritable traits), clinical manifestations, and specific physiological (i.e. brain functioning, affect regulation) characteristics. In that sense, the Greek NRNSS could inform clinical practice and offer research-wise potential utility in a wide array of cross-cultural experimental settings. 


\section{Declaration of conflicting interests}

The author(s) declared no potential conflicts of interest with respect to the research, authorship, and/or publi-cation of this article.

\section{Funding}

The author(s) received no financial support for the research, authorship, and/or publication of this article.

\section{ORCID iD}

Anna Polemikou (D) https://orcid.org/0000-0002-5369-7740

\section{Supplemental material}

Supplemental material for this article is available online.

\section{References}

Alivizatos, N. (1999). A new role for the Greek church? Journal of Modern Greek Studies, 17(1), 23-40. Baumgartner, H., \& Homburg, C. (1996). Applications of structural equation modeling in marketing and consumer research: A review. International Journal of Research in Marketing, 13, 139-161.

Bishop, B. (2018). Advocating for atheist clients in the counseling profession. Counseling and Values, 63, 17-30. doi:10.1002/cvj.12070

Brewer-Smyth, K., \& Koenig, H. G. (2014). Could spirituality and religion promote stress resilience in survivors of childhood trauma? Issues in Mental Health Nursing, 35, 251-256. doi:10.3109/01612840.2013.873101 Brown, T. A. (2015). Confirmatory factor analysis for applied research (2nd ed.). New York, NY: Guilford Press. Byrne,

B. M. (2016). Structural equation modeling with AMOS: Basic concepts, applications, and programming (3rd ed.). London, England: Routledge.

Coleman, T. J. I., Hood, R. W. J., \& Streib, H. (2018). An introduction to atheism, agnosticism, and nonreligious worldviews. Psychology of Religion and Spirituality, 10, 203-206. doi:10.1037/rel0000213

Connor, K. M., \& Davidson, J. R. T. (2003). Development of a new resilience scale: The Connor-Davidson Resilience Scale (CD-RISC). Depression and Anxiety, 18, 76-82. doi:10.1002/da.10113

Cragun, R. T., Hammer, J. H., \& Nielsen, M. (2015). The NonReligious-NonSpiritual Scale (NRNSS): Measuring everyone from atheists to zionists. Science, Religion \& Culture, 2(3), 36-53. doi:10.17582/ journal.src/2015/2.3.36.53

Cronbach, L. J. (1951). Coefficient alpha and the internal structure of tests. Psychometrika, 16, 297-334. doi:10.1007/BF02310555

Currier, J. M., Drescher, K. D., \& Harris, J. I. (2014). Spiritual functioning among veterans seeking residential treatment for PTSD: A matched control group study. Spirituality in Clinical Practice, 1(1), 3-15. doi:10.1037/ scp0000004

de Jager Meezenbroek, E., Garssen, B., van den Berg, M., van Dierendonck, D., Visse, A., \& Schaufeli, W. B. (2012). Measuring spirituality as a universal human experience: A review of spirituality questionnaires. Journal of Religion and Health, 51(2), 336-354. doi:10.1007/s10943-010-9376-1

Dianeosis. (2018). World Values Survey: Round seven-Country-pooled datafile (v.25.09.2018). Athens, Greece: Author. Retrieved from https://www.dianeosis.org/2018/09/oi-aksies-twn-ellinwn/

Dimitriadou, D., \& Stalikas, A. (2012). Connor-Davidson Resilience Scale (CD-RISC). In A. Stalikas, S. Triliva, \& P. Roussi (Eds.), Psychometric instruments in Greece (2nd ed., p. 717). Athens, Greece: Pedio.

Emmons, R. A. (1999). Religion in the psychology of personality: An introduction. Journal of Personality, 67, 873-888.

Gorsuch, R. L., \& McPherson, S. E. (1989). Intrinsic/extrinsic measurement: Scientific, I/E-Revised and single item scales. Journal for the Study of Religion, 28, 348-354.

Hu, L. T., \& Bentler, P. M. (1999). Cutoff criteria for fit indexes in covariance structure analysis: Conventional criteria versus new alternatives. Structural Equation Modeling: A Multidisciplinary Journal, 6, 1-55. doi:10.1080/10705519909540118 
Kapuscinski, A. N., \& Masters, K. S. (2010). The current status of measures of spirituality: A critical review of scale development. Psychology of Religion and Spirituality, 2, 191-205. doi:10.1037/a0020498 Kline, R.

B. (2016). Principles and practice of structural equation modeling (4th ed.). New York, NY: Guilford Press.

Lavrakas, P. J. (2008). Double-barreled question. In P. Lavrakas (Ed.), Encyclopedia of survey research methods. Thousand Oaks, CA: SAGE. doi:10.4135/9781412963947

Little, R. J. A. (1988). A Test of Missing Completely at Random for multivariate data with missing values. Journal of the American Statistical Association, 84(404), 1198-1202. doi: 10.2307/2290157

Liu, D. W. Y., Fairweather-Schmidt, A. K., Burns, R. A., \& Roberts, R. M. (2014). The Connor-Davidson Resilience Scale: Establishing invariance between gender across the lifespan in a large community based study. Journal of Psychopathology and Behavioral Assessment, 37, 340-348. doi:10.1007/s10862-014-9452-z

Lun, V. M. C., \& Bond, M. H. (2013). Examining the relation of religion and spirituality to subjective wellbeing across national cultures. Psychology of Religion and Spirituality, 5, 304-315. doi:10.1037/a0033641

Marangudakis, M., Rontos, K., \& Xenitidou, M. (2013). State crisis and civil consciousness in Greece (GreeSE: Hellenic Observatory Papers on Greece and Southeast Europe, 77). Retrieved from http:// eprints.lse.ac.uk/53727/1/GreeSE No77.pdf

Molokotos-Liederman, L. (2003). Identity crisis: Greece, orthodoxy, and the European Union. Journal of Contemporary Religion, 18(3), 291-315. doi:10.1080/13537900310001601677

Mrdjenovich, A. J. (2019). Religiously/spiritually involved, but in doubt or disbelief-Why? Healthy? Journal of Religion and Health, 58(5), 1488-1515. doi:10.1007/s10943-018-0711-2

Nunnally, J. C., \& Bernstein, I. H. (1994). The assessment of reliability. Psychometric Theory, 3, 248-292.

Pew Research Centre. (2018). Eastern and Western Europeans differ on importance of religion, views of minorities, and key social issues. Available from http://www.pewforum.org/

Pezirkianidis, C., Karakasidou, E., Galanakis, M., \& Stalikas, A. (2016). Validation of the Meaning in Life Questionnaire (MLQ) in a Greek sample. Psychology, 7, 1518-1530. doi:10.4236/psych.2016.713148

Saroglou, V. (2011). Believing, bonding, behaving, and belonging: The big four religious dimensions and cul-tural variation. Journal of Cross-cultural Psychology, 42, 1320-1340. doi:10.1177/0022022111412267 Saucier, G., \&

Skrzypinska, K. (2006). Spiritual but not religious? Evidence for two independent dispositions. Journal of Personality, 74, 1257-1292. doi:10.1111/j.1467-6494.2006.00409.x

Schnell, T. (2015). Dimensions of Secularity (DoS): An open inventory to measure facets of secular identities. The International Journal for the Psychology of Religion, 25, 272-292. doi:10.1080/10508619.2014.967541 Sevinc,

K., Metinyurt, T., \& Coleman, T. (2017). What is nonbelief? An empirical research on the concept of nonbelief. Turkish Journal of Religious Education Studies, 4, 23-40.

Silver, C. F., Coleman, T. J., Hood, R. W., \& Holcombe, J. M. (2014). The six types of nonbelief: A qualita-tive and quantitative study of type and narrative. Mental Health, Religion and Culture, 17, 990 1001. doi:10.1080/13674676.2014.987743

Solano-Flores, G., Backhoff, E., \& Contreras-Niño, L. Á. (2009). Theory of test translation error. International Journal of Testing, 9, 78-91. doi:10.1080/15305050902880835

Stalikas, A., Kyriazos, T. A., Yotsidi, V., \& Prassa, K. (2018). Using bifactor EFA, bifactor CFA and explora-tory structural equation modeling to validate factor structure of the Meaning in Life Questionnaire, Greek version. Psychology, 9, 348-371. doi:10.4236/psych.2018.93022

Steger, M. F., Frazier, P., Oishi, S., \& Kaler, M. (2006). The Meaning in Life Questionnaire: Assessing the presence of and search for meaning in life. Journal of Counseling Psychology, 53, 80-93. doi:10.1037/0022-0167.53.1.80 Tabei, S.

Z., Zarei, N., \& Joulaei, H. (2016). The impact of spirituality on health. Shiraz E Medical Journal, 17(6), e39053. doi:10.17795/semj39053

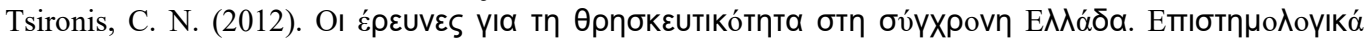
$\pi \rho \circ \varepsilon \varepsilon{ }^{\prime} \mu \varepsilon \vee \alpha$ [Research on religiosity in contemporary Greece. A preface on epistemology]. Culture and Research, 1, 67-82.

Van Cappellen, P., Fredrickson, B. L., Saroglou, V., \& Corneille, O. (2017). Religiosity and the motivation for social affiliation. Personality and Individual Differences, 113, 24-31. doi:10.1016/j.paid.2017.02.065

Van de Vijver, F., \& Hambleton, R. K. (1996). Translating tests: Some practical guidelines. European Psychologist, 1, 89-99. doi:10.1027/1016-9040.1.2.89 


\section{Appendix 1}

\section{Greek version of the Nonreligious-Nonspiritual Scale (NRNSS)}

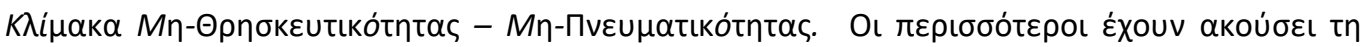

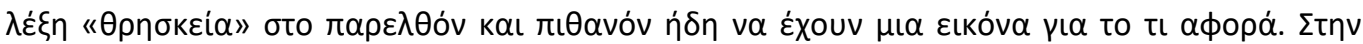

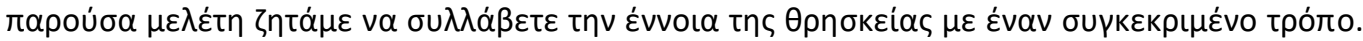

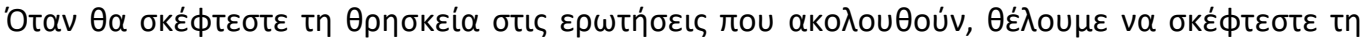

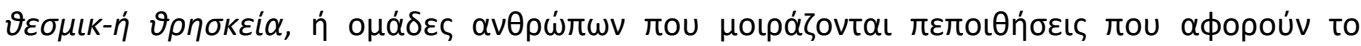

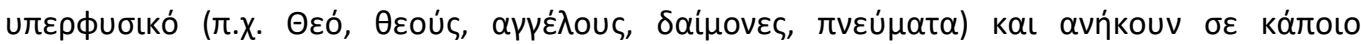

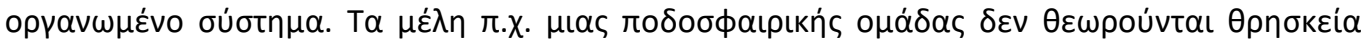

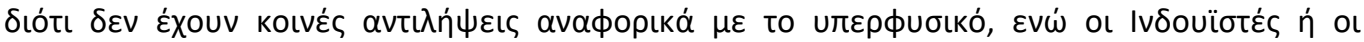

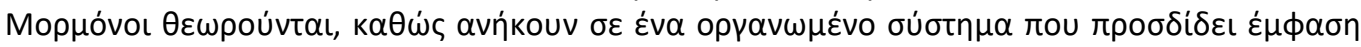

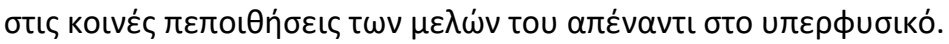

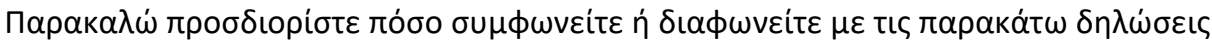

1.

$\Sigma \cup \mu \phi \omega v \omega \dot{~}$ $\alpha \pi \dot{\lambda} \operatorname{ut\alpha }$
2.

$\Sigma u \mu \phi \omega v \omega ́$
3.

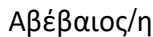

4. $\Delta\llcorner\alpha \phi \omega v \omega \dot{~}$
5. $\Delta \iota \alpha \phi \omega v \omega \dot{~}$

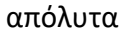

\begin{tabular}{|c|c|c|c|c|c|}
\hline 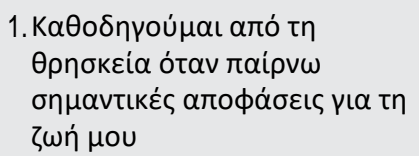 & $\square$ & $\square$ & $\square$ & $\square$ & $\square$ \\
\hline 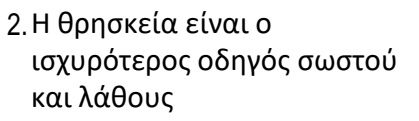 & $\square$ & $\square$ & $\square$ & $\square$ & $\square$ \\
\hline 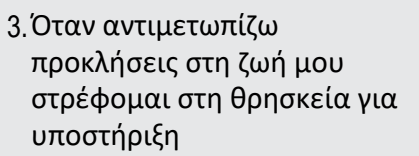 & 口 & $\square$ & $\square$ & $\square$ & $\square$ \\
\hline 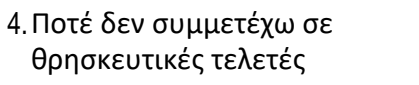 & $\square$ & $\square$ & $\square$ & $\square$ & $\square$ \\
\hline 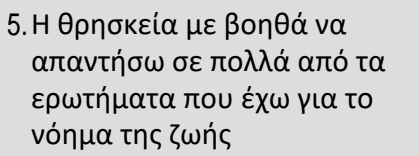 & 口 & $\square$ & $\square$ & $\square$ & $\square$ \\
\hline 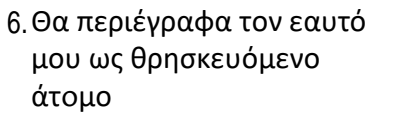 & 口 & $\square$ & 口 & $\square$ & $\square$ \\
\hline 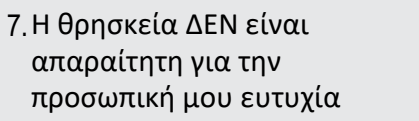 & $\square$ & $\square$ & $\square$ & $\square$ & $\square$ \\
\hline 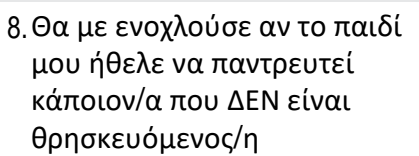 & $\square$ & $\square$ & $\square$ & 口 & $\square$ \\
\hline
\end{tabular}




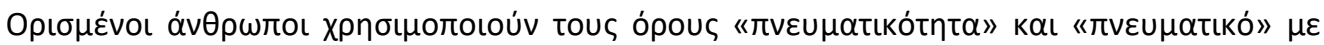

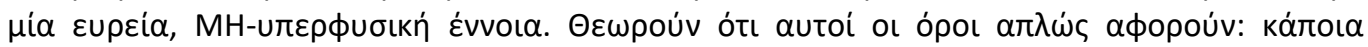

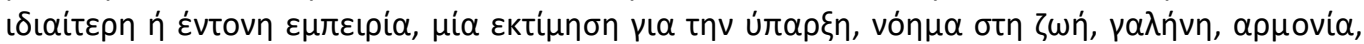

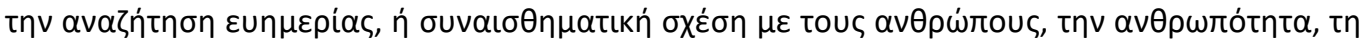

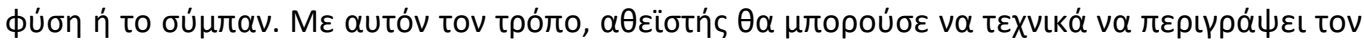

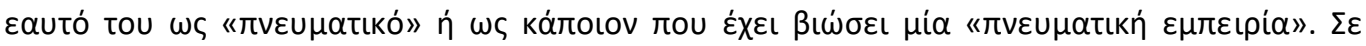

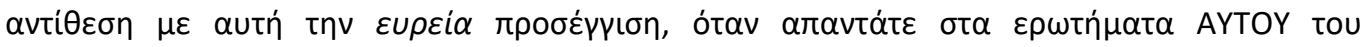

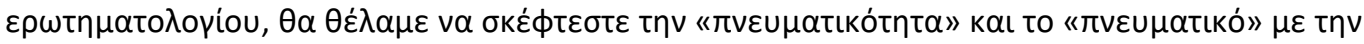

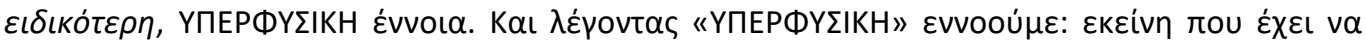

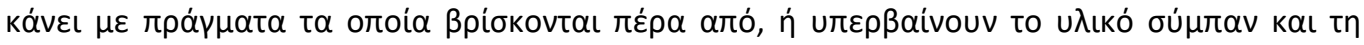

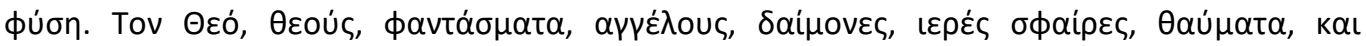

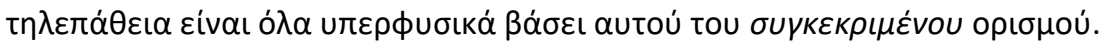

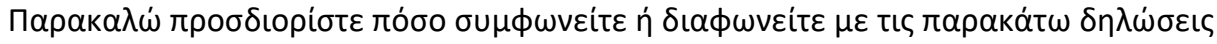

\begin{tabular}{|c|c|c|c|c|}
\hline 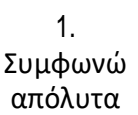 & $\begin{array}{c}2 . \\
\Sigma u \mu \phi \omega v \omega \dot{~}\end{array}$ & $\begin{array}{c}3 . \\
\text { A } \beta \dot{\beta} \beta \alpha \iota_{0} / \eta\end{array}$ & $\begin{array}{c}4 . \\
\Delta \iota \alpha \phi \omega v \omega \dot{~}\end{array}$ & $\begin{array}{c}5 . \\
\Delta\llcorner\alpha \phi \omega v \omega \dot{ } \\
\alpha \pi o ́ \lambda \cup \tau \alpha\end{array}$ \\
\hline
\end{tabular}

\begin{tabular}{|c|c|c|c|c|c|}
\hline 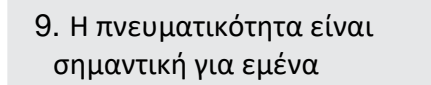 & $\square$ & $\square$ & $\square$ & $\square$ & $\square$ \\
\hline 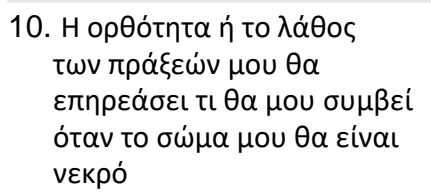 & 口 & $\square$ & $\square$ & $\square$ & $\square$ \\
\hline
\end{tabular}

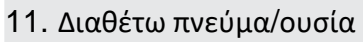

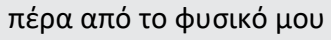
$\sigma \omega \dot{\mu} \mu \alpha$

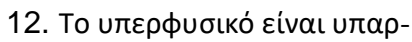
ктó

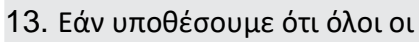

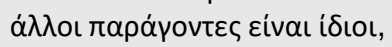

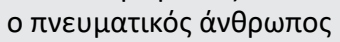

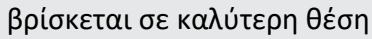

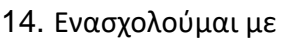

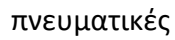

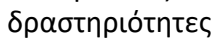

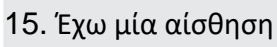

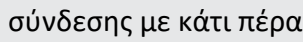

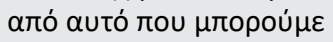

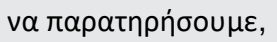

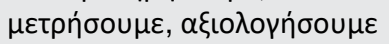

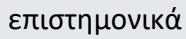

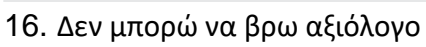

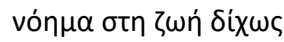

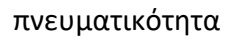

